\title{
Health Care Services for Children and Adolescents
}

\section{Citation}

Perrin, James, Bernard Guyer, and Jean M. Lawrence. 1992. “Health Care Services for Children and Adolescents." The Future of Children 2 (2): 58. doi:10.2307/1602562.

\section{Published Version}

doi:10.2307/1602562

\section{Permanent link}

http://nrs.harvard.edu/urn-3:HUL.InstRepos:30207917

\section{Terms of Use}

This article was downloaded from Harvard University's DASH repository, and is made available under the terms and conditions applicable to Other Posted Material, as set forth at http:// nrs.harvard.edu/urn-3:HUL.InstRepos:dash.current.terms-of-use\#LAA

\section{Share Your Story}

The Harvard community has made this article openly available.

Please share how this access benefits you. Submit a story.

Accessibility 


\title{
Health Care Services for Children and Adolescents
}

\author{
James Perrin \\ Bernard Guyer \\ Jean M. Lawrence
}

\begin{abstract}
The authors of this paper identify risks to health and other factors that determine the need for health care services among children and adolescents. They document service utilization patterns in the areas of well-child care and immunizations, acute ambulatory care and hospital services, and injury prevention. They also acknowledge the special health care needs of adolescents and of children with chronic illnesses.

It appears that neither the traditional personal health service delivery system nor the public health system alone can effectively provide all of the health services children need. Collaboration between public health and personal health service providers is essential to future efforts to improve the health of children and adolescents. Recommendations include development of community-based preventive care programs in all parts of the country, extension of current traditional primary care capabilities, assurance of access to primary care services, enhancement of public health activities, expansion of specialized adolescent health programs, and coordination of a comprehensive set of medical and other services for children with chronic illness and their families. The authors conclude that, to be effective, future health system reforms must be implemented through a coordinated program of care rather than through competing systems of services.
\end{abstract}

James Perrin, M.D., is associate professor of pediatrics at Harvard Medical School, Massachusetts General Hospital, Wang Ambulatory Care Center.

Bernard Guyer, M.D., M.P.H., is professor and chairman of the Department of Maternal and Child Health, at Johns Hopkins University. School of Hygiene and Public Health.

Jean M. Lawrence, M.S.S.A., M.P.H., is a doctoral candidate and research assistant, Department of Maternal and Child Health, at Johns Hopkins University School of Hygiene and Public Health.
$\mathbf{T}$ he control of infectious diseases and the recognition of the value of preventive care have dramatically changed the health care needs of children. Infectious diseases such as pneumonia and influenza accounted for about $25 \%$ of deaths of children from 1 through 5 years of age in 1950; by 1976, they accounted for less than $10 \%{ }^{1}$ Infant mortality rates in the United States dropped from 47 per 1,000 live births in 1940 to less than 10 in 1990. Postneonatal mortality rates (deaths to infants 28 days to 1 year old) dropped during the same period from 18.3 to 3.7 per 1,000 live births. (See the article by Racine, Joyce, and Grossman in this journal issue.) 
New problems-including injuries, the effects of environmental toxins, family violence, homelessness, and disorders of development-increasingly define health care issues for children today. Injuries have emerged as the major cause of childhood mortality, morbidity, and disability. ${ }^{3,4}$ Changing patterns of illness among adolescents have focused attention on tasks of healthy development, including the promotion of physical fitness and healthy sexual behaviors, and the prevention of injury, substance abuse, unwanted pregnancy, sexually transmitted disease, and violence, as reflected in homicide, suicide, and major trauma. (See the article by Starfield in this journal issue.)

Changing health care needs have led to changes in patterns of outpatient and inpatient hospital utilization. Physician and nursing services delivered in physicians' private offices, hospital outpatient departments, and clinics are increasingly preventive. In addition to routine immunizations, these services include behavioral counseling, parent education, and health promotion guidance to families. Rates of inpatient hospital care have declined, as have lengths of stay, indicating both the changing patterns of illness and also greater use of

Changing health care needs have led to changes in patterns of outpatient and inpatient hospital utilization.

ambulatory settings for the treatment of many acute and chronic health conditions. ${ }^{5,6}$ New technologies frequently play an important role when a child is hospitalized and when sophisticated care in the home and other nonhospital settings is needed. ${ }^{7}$

Other important trends in the past 2 decades include the growth of consumerism, increased survival of children with severe long-term illnesses, greater use of legislation and regulatory mechanisms to improve child health, and higher rates of childhood poverty. Consumerism has led to greater interest in self-care and care by parents. Parents and family members provide significant amounts of care for minor illnesses without direct contact with health providers. Children provide more of their own care as they mature, and the few data available suggest extensive treatment with over-the-counter medication. ${ }^{8,9}$ The family also has a major role in prevention, especially in promoting home safety, seat belt and bicycle helmet use, a healthy diet, and exercise.

Government programs and specific legislation to protect children have major impacts on the health of American children and on the service delivery system. Since the mid-1960s, Medicaid has become the 
major source of health insurance for poor children. (See the article by Hill in this journal issue.) Other federal and state programs, including maternal and child health programs and community health centers, provide access to primary health care services. ${ }^{10,11}$ Further efforts to protect children's health include legislation that requires packaging designed to prevent poisoning, ${ }^{12}$ flame retardant sleepwear, ${ }^{13}$ and automobile passenger restraints for children. ${ }^{14}$ Other health promotion efforts for children include the fluoridation of water and the federal vaccine program. Media campaigns linked to housing codes have led to lower water heater temperatures and decreased risks of childhood hot water scalds. ${ }^{15}$

The long-term survival of children with chronic illnesses and physical disabilities, some of whom have associated developmental disabilities, has greatly improved, ${ }^{16}$ and these changing rates affect the organization and provision of health services for children. Poverty among children may offset many of the advances in child health care, however. Poverty is associated with increasing rates of poor health and childhood disability ${ }^{17}$ (see the article by Starfield in this journal issue) as well as greater use of more expensive health care services, especially inpatient hospital and emergency room care. ${ }^{18}$

In this paper, we have three objectives: (1) to identify risks to health and other factors that define the need for health care services among children and adolescents; (2) to document service utilization patterns in relation to these needs and barriers to services; and (3) to argue that future efforts to improve the health of children and adolescents must focus on community-level outcomes and include multidisciplinary models of care.

\section{Risks to Health and the Need for Services}

Use of health services among children and adolescents is determined by a complex interaction among patterns of illness, protocols for preventive health care, features of third-party reimbursement plans, and factors that facilitate or create barriers to care.

\section{Infants, Preschool, and School-age Children}

Most childhood illnesses are self-limited, that is, they typically improve whether or not they are treated. The purposes of surveillance and treatment of these conditions are (1) to decrease pain and discomfort; (2) to decrease the impact of minor illnesses on daily life (such as school or child care attendance and interruption of parental routine, including work) by decreasing the severity of symptoms or the length of illness; (3) to minimize consequences or complica- tions of illness (such as the treatment of streptococcal infections to prevent rheumatic fever); and (4) to identify the relatively rare serious condition among the much larger number of minor illnesses.

The health care needs of children are not defined by the patterns of injury and disease conditions alone. New morbidity conditions-including behavior disorders, disorders of development, adjustment problems in adolescence, psychosocial issues related to chronic illness, family violence, and abuse, and exposure to environmental hazards ${ }^{19}$ such as lead-may also respond to medical care. ${ }^{20}$ Figure 1 provides estimates of the relative prevalence of several of these conditions.

To some degree, changing utilization patterns of personal health services reflect this changing morbidity, although these changes may be poorly described in studies of child health services utilization. (See the article by Starfield in this journal issue.) Many physicians have had 
little training in these new areas, such as in responding to the more than 1 million children nationwide who experience abuse or neglect. ${ }^{21}$ The current limited reimbursement for care of some of these conditions also discourages practitioners from using these labels to define the reasons for visits with the result that their true prevalence is underestimated. Current efforts to expand coding mechanisms for childhood behavioral and developmental conditions may positively affect identification and reimbursement. ${ }^{22,23}$

Routine programs of screening have become an integral part of the delivery of child health services. Since 1961, when screening for phenylketonuria (PKU) began, the availability of simple screening procedures for the detection of inborn errors of metabolism in the neonatal period has resulted in a decrease in the number of infants suffering the adverse effects of preventable conditions. Screening for PKU and congenital hypothyroidism is routinely conducted in all 50 states and the District of Columbia. Approximately 4,500 cases of diseases that can lead to death or mental retardation are detected each year through the use of newborn screening. ${ }^{24}$
Routine preventive health care can be scheduled at intervals corresponding to the recommended immunizations against diphtheria, pertussis, and tetanus (DPT); poliomyelitis; hemophilus influenza; and measles, mumps, and rubella (MMR). Immunization against hepatitis $B$ has recently been added to recommendations. Beyond immunizations, children may also be screened for specific illnesses or health conditions, including lead intoxication, hearing and visual problems, scoliosis, tuberculosis, and iron deficiency anemia. ${ }^{25}$ Also recommended are targeted screening for sickle cell disease and for hypercholesterolemia. In addition, pediatric practice is an appropriate setting for assessing risks of developmental, behavioral, and educational problems, and for searching for problems in the family, such as parental depression, substance abuse, physical and sexual abuse, or smoking.

\section{Content of Well-child Care}

The content of well-child care can be assessed in two broad areas: reducing child mortality and morbidity, and promoting optimum growth and development. ${ }^{26}$ The goal of reducing child mortality and morbidity includes disease detection through the physical examination and other

\section{Figure 1. New Morbidities of Childhood}

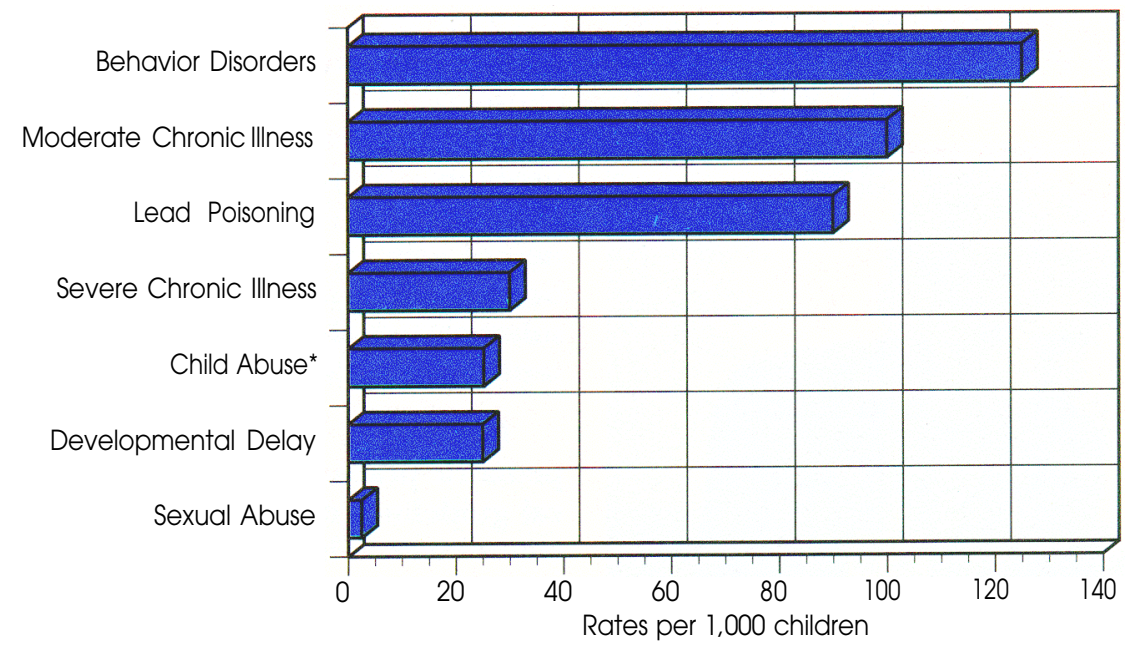

*Does not include sexual abuse

Source: U.S. Department of Health and Human Services. Healthy People 2000 National Health Promotion and Disease Prevention Objectives. Washington, DC: U.S. Government Printing Office (DHHS PHS 91-50212), 1991; Newacheck, P.W., and Starfield, B. Morbidity and Use of Ambulatory Care Services Among Poor and Non-poor Children. American Journal of Public Health (1988) 78:927-33. 
screening mechanisms and disease prevention through immunization. Despite a substantial literature which shows that few physical abnormalities are discovered during the routine well-child physical examination, ${ }^{24,26,27}$ this aspect of well-child care continues to occupy the bulk of time in physician visits. ${ }^{28}$

The Committee on Practice and Ambulatory Medicine of the American Academy of Pediatrics (AAP) currently recommends six well-child visits during the first year of life, six visits over the next 4 years, and visits every other year to age 20. In addition, the AAP recommends one maternal prenatal visit to a pediatrician for anticipatory guidance (for example, what to expect regarding sleep and crying patterns and how to cope with them) and to collect the pertinent medical and family history. ${ }^{29}$ (See the article by Racine, Joyce, and Grossman in this journal issue.) The guidelines recommend taking a history and measurements (height, weight, head circumference through the first year of life, and blood pressure after age 3), as well as developmental and behavioral assessments, physical examination, and anticipatory guidance (including counseling on feeding and sleeping habits, accident prevention and safety, behavior, and sex education). A typical wellchild visit lasts 10 to 12 minutes and may include laboratory work and other health screening measures. ${ }^{28}$

Observation of physician-patient interactions in private pediatric practices has found that anticipatory guidance ac- counted for $8.4 \%$ of the total time spent during well-child care visits. The time spent on anticipatory guidance varied from $1 \frac{1 / 2}{2}$ minutes per visit with parents of children under 5 months of age to $7 \mathrm{sec}-$ onds with adolescent patients. ${ }^{28}$ Increased utilization of pediatric nurse practitioners may be a cost-effective way to increase the educational component of well-child care. Research suggests that nurse practitioners provide parent education that is comparable to that provided by pediatricians, but their visits are longer because they tend to discuss developmental and behavioral issues in greater depth and to give parents more opportunity to talk. ${ }^{30}$

Immunization and promotion of preventive health behaviors are the major rationales for well-child care. Immunization against childhood infectious diseases is the single most effective and cost-effective intervention available to reduce morbidity and mortality. ${ }^{24}$ Other preventive interventions, however, are less well addressed in well-child care. Only 4 seconds of the well-child visit, on average, are devoted to injury prevention, even though injuries are the leading cause of death and disability in childhood. ${ }^{28}$

The second broad area of well-child care-promoting optimum growth and development-encompasses counseling about mother-child interaction, developmental advice, and parenting advice. The goals of this component of pediatric practice are poorly defined. De facto, pediatricians find themselves giving psychosocial guidance, offering advice on emotional disorders, and counseling for problems in family relationships and child behavior. ${ }^{31}$ Although the effectiveness of such clinical interventions has not been adequately studied, there is a substantial professional and parental consensus about their importance.

In general, counseling and advice in pediatric practice is based upon the clinical guidelines developed through expert committees. These guidelines represent state-of-the-art advice from the best available clinical experience and the shared cumulative experience of clinicians and academicians. They lack a strong empirical base because no randomized clinical trials have been carried out to evaluate the efficacy of pediatric counseling interventions in improving the health status of children. We believe, however, that the absence of a strong empirical research 
base in this area of child health care does not necessarily lead to the conclusion that these activities are not worthwhile, as was prematurely concluded by the Office of Technology Assessment in 1989. Further research is needed to evaluate both the recommended guidelines and the care that is actually being provided.

All the benefits of well-child care have not been clearly articulated. In addition to helping prevent premature death or serious illness, well-child care may offer support and reassurance for families and provide a "medical home" for parents if their child develops an acute illness. The medical home promotes continuity of care and provides the physician with baseline measures of the child's health status before the onset of illness. ${ }^{32}$ Identifying serious conditions is sometimes complex: fever and irritability in a very young child usually indicate a minor viral illness, but they may indicate a far more severe and life-threatening disease, such as meningitis or sepsis. As with much else in medical care, demonstrated efficacy of treatment for many common childhood illnesses is either limited or lacking. ${ }^{33}$

\section{Sources and Utilization of Health Care for Children}

Health services for children are available from several sources. For most children, a community-based physician (usually a pediatrician or family practitioner) provides most care, including preventive services (immunizations and anticipatory guidance) and care for most common illnesses. Although the majority of communitybased pediatric care is supported through some form of fee-for-service payment, increasing numbers of children receive care through prepaid programs, mainly health maintenance organizations (HMOs). (See the article by Sheils and Wolfe in this journal issue.)

Other important sources of general pediatric care are community health centers and public health departments. Community health centers may integrate general health services with different combinations of community preventive services, linking, for example, Women, Infants, and Children (WIC) nutrition programs, social services, and mental health programs, among others. Community health centers usually serve high-risk communities with high rates of poverty and environmental and social risks affecting child health. Medical services provided in health centers are supported by third-party payers (mostly public, through Medicaid), by fees collected from patients (frequently on a sliding scale pegged to income), and by direct service grants (especially through the federal community health centers program).

Coordination among preventive and treatment services may be substantial in some places, absent in others.

In some communities, a full range of preventive and treatment services is readily available. Other communities may lack major components or have major access barriers to immunizations or other services. Coordination among preventive and treatment services may be substantial in some places, absent in others. In most European countries some form of community-based preventive or general health care is available to all residents, regardless of social or economic status. ${ }^{34}$ Many U.S. communities lack similar services, and children thereby either go without services or receive them in settings designed for other purposes, such as hospital emergency rooms.

Most private health insurance programs cover illness care for children, but many do not cover the costs of preventive services such as immunizations. HMOs, which incorporate both insurance and organizational functions, typically do cover the costs of preventive care for children. Medicaid, the main public insurance program for low-income children, also pays for preventive care, including immunizations. Variations in public financing also affect children's access to preventive health care. To receive immunizations in traditional fee-for-service practice settings, parents usually pay directly for the service. In some communities, public health departments offer free immunization clinics. ${ }^{35}$ Other communities lack the budgets to provide such services to many children who need them. In some parts of the country, especially the rural South, health departments provide a broader range of general child health services, including both preventive and treatment services, either free of charge or on a sliding-fee scale. ${ }^{35}$ Nonfinancial barriers such as culture or geography may, however, also limit access, 
especially in community health centers. (See the articles by Sheils and Wolfe, Hill, and Klerman in this journal issue.)

The data on utilization of preventive services by young children are disturbing. Using data from the 1987 National Medical Expenditure Survey (NMES), Lefkowitz and Short found that a significant proportion of 2-year-old children did not receive preventive health care. ${ }^{36}$ Twenty-five percent of Medicaid children, $30 \%$ of uninsured children, and $20 \%$ of insured children had not had a preventive health care visit during the previous year. When examining the rate of preventive visits by racial and/or ethnic groups, Lefkowitz and Short found that $20 \%$ of white children had received no preventive health care visits, whereas $33.4 \%$ of black children and $33.0 \%$ of Hispanic children had made no preventive visits to a health care provider.

Data from the 1989 National Health Interview Survey (NHIS) indicate that, on average, children 0 to 5 years of age have about 4.1 physician visits annually, and children 5 to 17 years of age have 2.2 visits per year. When telephone and hospital physician contacts are included in the number of physician contacts, these figures increase to 5.8 and 3.1 contacts per year, respectively. ${ }^{37}$

Visits vary by family income, race, and insurance status. Children under 18 years of age whose family yearly income is under $\$ 10,000$ have 2.3 office visits per year (or 3.6 total contacts), whereas children whose annual family income is between $\$ 10,000$ and $\$ 19,999$ have 2.1 office visits per year (or 3.3 total contacts). ${ }^{37}$ This difference serves as an illustration that the near-poor (the most likely to be uninsured) have fewer health care visits than do the poor, who have Medicaid to pay for their health care. Monheit and Cunningham in this journal issue provide a detailed analysis that confirms the relationship between insurance status and the utilization of medical services by children. White children under age 18 make 3.0 office visits (4.2 total contacts), whereas black children in the same age category make 1.6 office visits $\left(2.5\right.$ total contacts). ${ }^{37}$

\section{Hospital Services}

Rates of hospitalization and lengths of hospital stay have declined for both children and adults over the past decade.

\section{Figure 2. Major Causes of Adolescent (10-19 Years Old) Mortality, 1985}

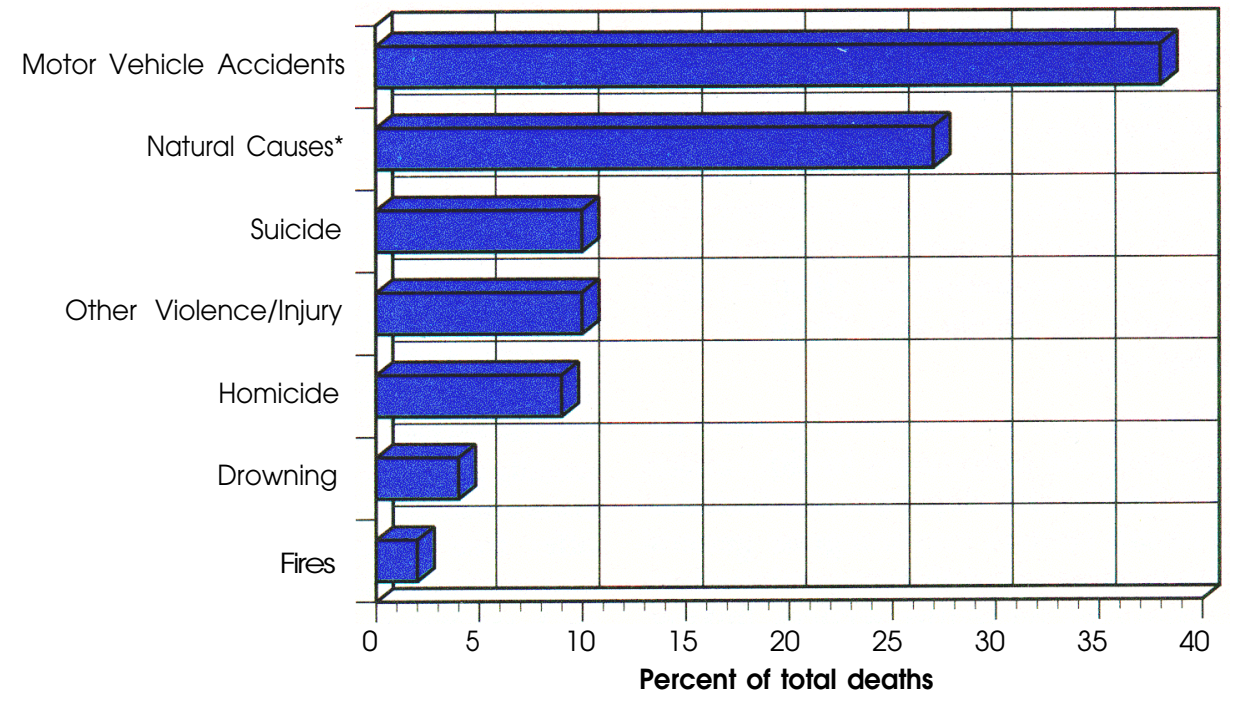

*Including neoplasms, congenital anomalies, and a number of relatively rare conditions.

Source: Fingerhut, L., and Kleinman, J. Trends and Current Status in Childhood Mortality, U.S., 1900-1985. Vital and Health Statistics. Series 3, No. 26 (DHHS Pub No. 89-1410). Hyattsville, MD: National Center for Health Statistics, 1989. 
Approximately 2.4 million children under age 15 years were hospitalized in 1990, representing a decline of about $29 \%$ from $1984 .{ }^{5}$ Children utilize a relatively small proportion of total acute hospital care (less than $8 \%$ of total hospital discharges). Data from the 1990 National Hospital Discharge Survey indicate an overall average of 0.21 hospital days per child per year.

The number of children in hospitals with chronic health conditions rather than acute ones has been increasing. Recent estimates at specialty hospitals suggest that about $70 \%$ of all childhood admissions currently are for chronic conditions. ${ }^{38}$ Major advances in medical and surgical technology have led to the survival of a greater number of severely ill children. Technological advances, especially miniaturization of complex equipment, have also increasingly allowed technologydependent children to receive care in home and community settings.

Recent studies have demonstrated sizeable variations in rates of hospitalization for children. ${ }^{18}$ Children residing in Boston, Massachusetts, for example, have about three times the risk of hospitaliza- tion for medical problems as do children in Rochester, New York. These communities have similar medical resources, as indicated by per capita physician and hospital bed rates, but the Boston population is poorer than that of Rochester. Because poverty increases children's risks of hospitalization, variations in poverty levels among communities may explain some but not all of the variations in rates of hospitalization. Other causes likely include the availability and types of community-based general health services for nonpoor children and physician practice style. Children who lack regular community-based physician care are more likely to use emergency rooms ${ }^{39}$ and are more likely to be admitted to the hospital when they do.

\section{Adolescents}

Adolescents, 10 through 19 years old, represent the only segment of the U.S. population in which mortality rates have not declined rapidly during the past 2 decades. ${ }^{3}$ The major causes of mortality during adolescence are motor vehicle accidents $(38 \%)$, natural causes $(27 \%)$, suicide $(10 \%)$, other violence and injuries

\section{Figure 3. Estimated Prevalence of Adolescent (10-19 Years Old) Health Problems**}

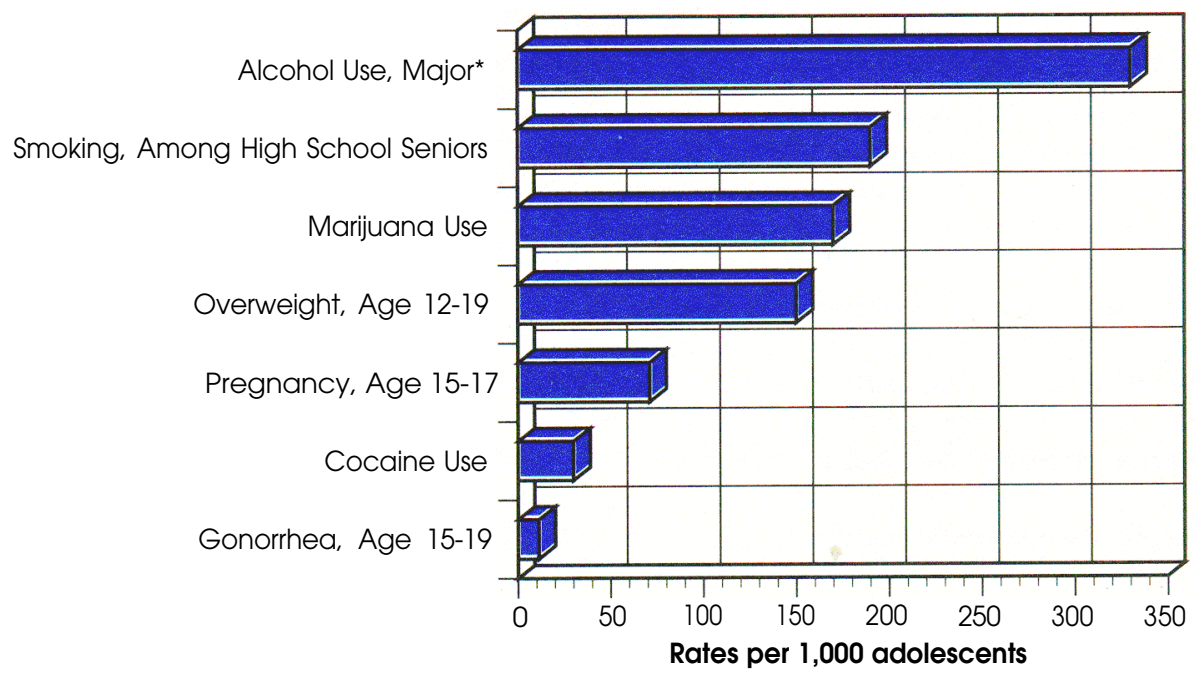

*High school seniors having five or more drinks in the past 2 weeks ${ }^{* *}$ Composite of dates, but basically 1976-1989

Source: U.S. Department of Health and Human Services. Healthy People 2000 National Health Promotion and Disease Prevention Objectives. Washington, DC: U.S. Government Printing Office (DHHS PHS 91-50212), 1991. 
(10\%), homicide (9\%), drowning (4\%), and fires $(2 \%)^{3}$ (see figure 2 ). Half of the motor vehicle accidents that result in the death of an adolescent involve alcohol. ${ }^{40}$ Thus, $73 \%$ of the deaths that occur between the ages of 10 and 19 years can be attributed to intentional and unintentional injuries and violence. Many of the behaviors that lead to these deaths can be targets of prevention and intervention activities by the health care system, the community, and individual health care providers.

Seventy-three percent of the deaths that occur between the ages of 10 and 19 years can be attributed to intentional and unintentional injuries and violence.

Goals for adolescent health go well beyond the prevention of violence and injury to include developing healthy behaviors related to sexuality, physical fitness, and dietary habits, and preventing substance abuse. Issues related to sexuality include prevention of unwanted teenage pregnancy (and the subsequent choices regarding parenting, adoption, or abortion if pregnancy does occur) and sexually transmitted diseases, including HIV infection (see figure 3). To have an impact, education regarding these issues should start prior to adolescence, when children are beginning to think about these behaviors.

Addressing the health care needs of adolescents may necessitate modification of some sectors of the health care system to accommodate their special circumstances. (See the article by Klerman in this journal issue.) Barriers to the effective use of traditional health care services by adolescents include discomfort with traditional health care settings, lack of insurance coverage or money to cover the cost of care, parental consent requirements for some services, lack of office hours that do not conflict with school hours, and the inability or refusal of some adolescents to comply with the recommended medical treatment or follow-up. ${ }^{42}$ Many adolescents either do not use medical services or, when they do, receive little help for their special problems. Physicians may represent parent-surrogate authority figures for many adolescents, affecting adolescents' comfort in medical settings. In addition, a greater need for privacy-a normal part of adolescent developmentmakes issues of sexuality, drug and alcohol use, cigarette smoking, and other behaviors that expose them to health risks difficult to disclose to health care providers. Finally, many physicians remain uncomfortable or unskilled in addressing these issues with their adolescent patients. ${ }^{43}$ As a result, adolescents between the ages of 10 and 18 make only 1.6 visits to an officebased physician each year. White adolescents make 1.7 visits, compared with 0.9 visits made by black adolescents. ${ }^{44}$ With this limited number of contacts, traditional health care providers may have little impact on many problems experienced by adolescents.

Moreover, adolescents are not a homogeneous population. Among the adolescents at highest risk for poor health outcomes are homeless and runaway youths. Up to one million youths run away from home each year. ${ }^{45}$ Among homeless and runaway youths, $48 \%$ are depressed, $46 \%$ have substance abuse problems, $31 \%$ have been victims of physical abuse, $21 \%$ sexual abuse, $58 \%$ have school-related problems, and $9 \%$ have engaged in sexual activity (prostitution) to survive on the streets. ${ }^{46}$ Yet, despite the high-risk emotional and behavioral profile of this population, access to and utilization of health services are low because many of the same barriers that limit effective use of health services by adolescents living in intact families present even more formidable obstacles to homeless and runaway youth. $^{47}$

\section{Integrating Services in the Community}

Even where an effective intervention such as immunization exists to protect the health of children, the traditional organization of health care services has failed to assure the availability of the intervention to all children. In addition, traditional practice patterns may be inadequate to protect children and adolescents from broader risks, such as exposure to injuries. These observations lead us to support an expanded approach to child health care that integrates the roles of the office- and clinic-based pediatric practitioners with community-based child health practitioners. Similarly, responsive preventive care for adolescents may require a departure from traditional models. 
Infants, Preschool, and School-age Children

Multidisciplinary models of care may be needed to improve the health status of all children. Such models already exist in most Western European countries. ${ }^{34,48}$ This concept can be demonstrated by examining the coordinated responses of public and private health providers at the community level which are necessary to achieve recommended levels of immunization by 2 years of age and to protect school-age children from the risk of injury.

\section{Immunizations}

The United States has an enviable record of achieving very high levels of immunization of school-age children. All states require that a child receive a basic set of immunizations as a condition of school entry, and, as a result, U.S. immunization rates for school-age children are generally higher than those of most other industrialized countries. ${ }^{49}$ Nonetheless, data from the 1985 national immunization survey (the most recent source of national data on immunization status) showed that, among children 1 to 4 years old, 21.2\% were not immunized against measles, $24.3 \%$ were inadequately protected against polio, and $13 \%$ were inadequately protected against diphtheria, pertussis, and tetanus. ${ }^{50}$ By 1990, the proportion of low-income, inner city children fully immunized against all the vaccine-preventable diseases by age 2 years was estimated to have fallen to less than $50 \%{ }^{51}$ As a result of low and declining levels of immunizations during the 1980s epidemics of measles occurred in 1989 and 1990, with 18,193 and 27,672 cases reported in those years. ${ }^{51}$ Nearly half of these cases $(48.1 \%)$ occurred in children less than 5 years of age. More than one third of the children in the age group who contracted measles in 1990 were eligible for vaccinations but had not been vaccinated.

Moreover, the United States failed to meet a key immunization objective for the year 1990: that by 2 years of age, $90 \%$ of children would be immunized against the major childhood diseases, particularly measles. ${ }^{49}$ Thus, for the single most accepted and cost-effective component of well-child care-routine immunizationthe health care system has failed to achieve national objectives, failed to maintain the professionally recommended immunization schedule, and failed to protect young children from the threat of disease.

Immunization coverage of a population is a function of three interlocking domains: (1) health-seeking behavior on the part of parents of young children, (2) barriers to care, and (3) provider practices that inhibit appropriate immunization. ${ }^{52}$ Each of these domains appears to contribute to the failure to assure adequate immunization levels, although their relative contributions are not known.

Poor children are less likely to be immunized because they receive less preventive health care overall, stemming, in part, from negative family attitudes toward health care, disbelief in susceptibility to disease, or a feeling of powerlessness to prevent disease. ${ }^{53}$ Marks and colleagues found that low maternal education was a risk factor, implying that a clear understanding of immunization as an effective protection against disease was lacking in these mothers. ${ }^{54}$

The U.S. health care system is not equally accessible to all children. Dutton has linked low utilization among the poor to access barriers. ${ }^{53}$ (See the article by Klerman in this journal issue.) In the face of financial barriers to appropriate immunization, many families now seek care from publicly subsidized maternal and child health centers, community health centers, or county health departments. Unfortunately, users of these facilities often face inadequate supplies of vaccine, inconvenient hours and locations, and long waiting times. ${ }^{55}$ 
Overall, however, variation in office and clinic practices among primary and preventive health care providers may be the most important component of the failure of the health care system to assure adequate immunization coverage. Studies

\section{Variation in office and clinic practices among} primary and preventive health care providers may be the most important component of the failure of the health care system to assure adequate immunization coverage.

by the Centers for Disease Control of recent measles outbreaks in Puerto Rico, Miami, and Los Angeles found that one third of children who had failed to receive a measles, mumps, and rubella (MMR) vaccination had actually presented themselves for preventive care at the appropriate time, but their providers had missed opportunities to immunize them. ${ }^{56}$ These observations are consistent with earlier research. ${ }^{56,57}$ In addition, the use of multiple providers, which reduces the continuity of care, decreases the likelihood of adequate immunization. ${ }^{58}$ Finally, lack of knowledge among some physicians about scheduling, contraindications, proper vaccine storage, and potential complications may be associated with lower rates of immunization among children. $^{59}$

A successful community-based immunization program must include an accessible system of comprehensive primary health care, coordination between pediatric and public health practitioners, community surveillance of immunization status, an interactive information system containing the immunization status of each child that is accessible to all providers, and incentives to families to seek preventive health services for immunization beginning by the second month of life. Efforts to link adequate immunization to child care entry or to participation in benefit programs like WIC or Aid to Families with Dependent Children (AFDC) have also been recommended. ${ }^{55}$

\section{Injury Prevention}

The major threats to the health of children 5 to 14 years of age are pedestrian, motor vehicle occupant, bicycle-related, and recreational and sports-related injuries. In 1988, 4,990 children 5 to 14 years old died of injuries, 837 as pedestrians, and 940 as motor vehicle occupants. ${ }^{60}$ Sports-related injuries were estimated to account for more than 90,000 inpatient admissions and 2.5 million emergency room visits in 1985. ${ }^{4,61}$

Although child health care providers have often been in the forefront of community efforts to protect children (witness the role of Dr. Robert Saunders of Murfreesboro, Tennessee, in advocating for the nation's first child passenger safety legislation in 1978), they have generally relied upon office-based anticipatory guidance as their method for influencing child safety, with mixed results. ${ }^{62}$ Despite efforts by the AAP to promote a comprehensive program of office-based injury counseling, The Injury Prevention Program (TIPP), relatively few pediatricians actively use the program, and few alternatives are available. Studies are currently under way to explain the failure of pediatricians to use TIPP. ${ }^{63}$

Bicycle safety is an area in which child health care providers must join efforts with public health and other community-based agencies to address childhood injury successfully. There is now good evidence that safety helmets reduce the risk of brain injuries in falls from bicycles by as much as $85 \%$, ${ }^{64}$ yet fewer than $10 \%$ of bicycle riders of all ages wear helmets. ${ }^{65}$ One recent study found convincing evidence that a low-cost classroom intervention succeeded in promoting helmet use among elementary school pupils. ${ }^{66}$ Unfortunately, several controlled studies of bicycle helmet promotion in physicians' offices and emergency rooms have not demonstrated successes. ${ }^{67,68}$ As Runyan and Runyan concluded, physicians must not abandon their efforts to educate families about these risks, but must, in addition, join community-wide efforts to promote safety through legislation, regulations, school-based educational efforts, and improved environmental efforts. ${ }^{69}$ Health care professionals at all levels must find opportunities to build community coalitions involving medical care providers, school officials, parents, and public health agencies.

\section{Adolescents}

For many adolescents, the current system that delivers care through private physician practices, community health centers, and adolescent health programs works well. Rates of serious illness among 
adolescents are low, and the tasks of adolescent health care typically focus on prevention and encouragement of healthy life-styles. Effective programs for adolescents help them to develop self-care skills, encourage exercise and appropriate diet, and decrease major risks to health such as smoking, alcohol use, and other substance abuse. Further preventive care typically includes preparing adolescents for healthy sexual activity and teaching them methods of early identification of disease, such as through breast or testicular self-examination.

Alternative programs have been developed in response to the difficulties some adolescents have in accessing health care. These programs include specific clinics for adolescents in areas where they often congregate (such as shopping malls) and school-based clinics that are available during and after school hours. (An analysis of school-based clinics appeared in the Spring 1992 issue of The Future of Children.) Further, health services are needed for hardto-reach adolescents, such as homeless, runaway, and incarcerated youth. ${ }^{70}$ Unfortunately, few adolescents have access to services that are especially designed to meet their health care needs. School-based clinics exist in fewer than 200 of the 16,000 school districts nationwide. ${ }^{71}$

An evaluation of the impact of 23 school-based clinics on access to health care for adolescents from low-income households found that many of those enrolled in the clinics were previously medically underserved. ${ }^{71}$ Twenty-one percent had no regular source of medical care, $58 \%$ were self-pay (likely to be uninsured), and $21 \%$ had made no health care visits in the past 2 years. These clinics provided comprehensive services. Of the primary reasons for visits to these clinics, $26 \%$ were for acute injury and illness, $21 \%$ for mental health, and $12 \%$ for other categories including reproductive health care, physical exams, immunizations, and hearing and vision screening. Alcohol and drug abuse services constituted only $1 \%$ of the primary reasons for a visit.

Community and public support has been highly variable for these services, in part reflecting the controversy over providing contraceptive devices-including condoms and prescriptions-in school settings. The emphasis on the family planning role of school-based clinics conceals the fact that $80 \%$ of the main reasons for visits to these clinics concerned issues other than family planning. ${ }^{47}$ European countries provide universally available community-based preventive services, which provide many preventive services to adolescents. ${ }^{72}$ Similar forms of preventive care are not available in most communities in the United States.

The high-risk behaviors engaged in by some adolescents cannot be addressed solely or sufficiently by the health care system. A multifaceted intervention approach that is available, accessible, and affordable is needed to address the needs of adolescents. Increasing numbers of specialists in adolescent medicine may also help to focus attention on the development of new interventions to improve adolescent health.

\section{Children with Special Needs: The Case of Chronic Illness}

Some children's health problems make special demands upon children's health services. These conditions include chronic or catastrophic illness, major trauma, developmental disabilities, and children at environmental and social risk. We focus here on the example of childhood chronic illness as it illustrates the implications of these categories of special need.

Between $10 \%$ and $30 \%$ of all U.S. children have some kind of chronic health impairment, although the large majority of these conditions are mild and have little impact on children's daily activities or 
utilization of health services. ${ }^{73,74}$ About $10 \%$ of children with chronic illnesses, or perhaps 2 million children nationwide, have severe conditions that require extensive health services. (See the article by Starfield in this journal issue.) Of this group, only asthma and common (and usually less severe) forms of congenital heart disease occur with any great frequency. As figure 4 indicates, other individual conditions-such as leukemia, arthritis, diabetes, cystic fibrosis, epilepsy, and kidney failure - are rare. Estimates of the utilization of services by this population vary, but they generally suggest that the approximately $2 \%$ of children with severe illnesses use at least $25 \%$ of the child health dollar. ${ }^{75}$ This figure represents, in part, the higher-than-average utilization of inpatient hospital care by this group of children. (See the article by Lewit and Monheit in this journal issue.)

Although a common view is that many children with severe chronic illnesses die in childhood, current estimates of survival suggest that at least $90 \%$ of children, even with very severe long-term illnesses, survive to young adulthood. ${ }^{16}$ These rates reflect

\section{Figure 4. Estimated Prevalence of Childhood Chronic Illnesses*}

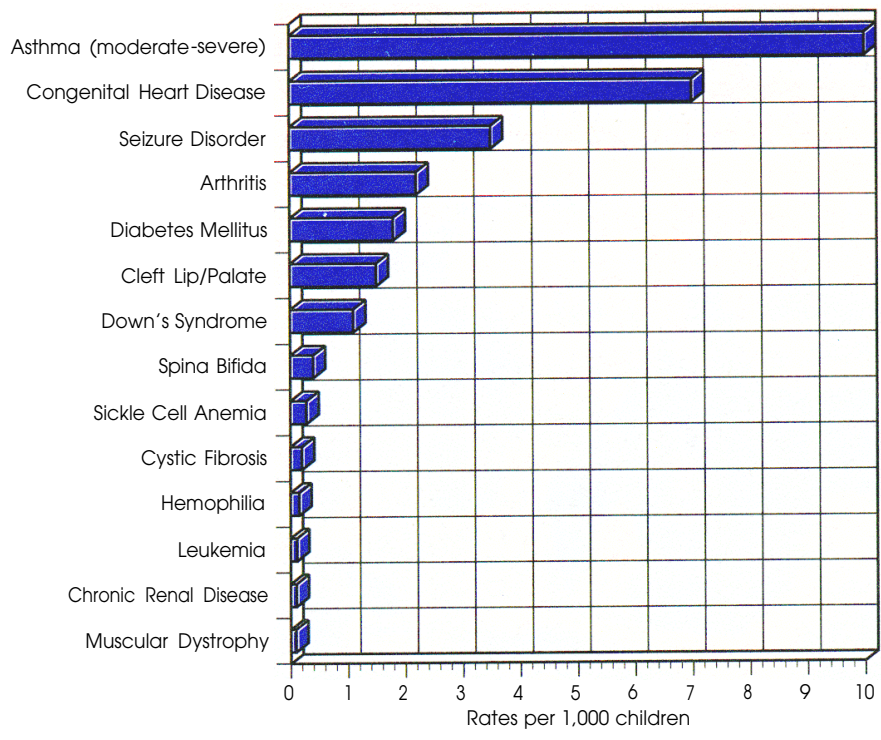

*Composite of dates, but basically 1979-1981.

Source: Gortmaker, S.L., and Sappenfield, W. Chronic Childhood Disorders: Prevalence and Impact. Pediatric Clinics of North America (1984) 31:3-18. a dramatic change in the past quarter century, brought about by major improvements in medical and surgical technologies and in the distribution and availability of sophisticated medical care. Indeed, these remarkable survival rates reflect some of the important successes of U.S. health care. Thus, where until relatively recently the emphasis was on improving survival rates, the emphasis now is on improving the quality of life for the large majority of chronically ill children who survive to become young adults, most of whom can participate as active members in most aspects of adult life.

AIDS creates challenges for households and health services similar to those from other chronic illnesses, with some important distinctions. First, AIDS in children is highly concentrated in poor and minority families. ${ }^{76}$ The disease had by 1988 become the first and second leading cause of death among Hispanic and African-American children, respectively, ages 1 through 4 in New York State. ${ }^{77}$ Second, it carries a very high fatality rate, with few infected children currently expected to survive to adulthood. Third, its main mode of acquisition (congenitally from infected mothers) means that other family members (especially mothers) may also be ill and therefore unable to care for their children. By late 1991 it was estimated that $10 \%$ of all pediatric hospital beds were occupied by children with AIDS. ${ }^{78}$ Currently affecting fewer than 1 in 20,000 children, AIDS will likely increase in prevalence, and treatment advances will likely improve survival rates among infected children. These trends, if realized, will probably increase the demands placed on the health care system for services for children with AIDS and for those infected with HIV.

Families provide substantial care for children with special health needs. Studies by Breslau and colleagues indicate that mothers spent significantly increased time at home caring for children with chronic illness and were less likely to be employed outside the home. ${ }^{79}$ The children in these studies were mainly ones with moderately severe illnesses. In recent years, many children with much more severe illnesses, including many dependent on major technologies, such as respirators or intravenous or tube feedings, have received care at home. Many of these children require extensive nursing care, monitoring, and the use of complicated equipment, 
often around-the-clock. This move toward increased home care is the result of several factors: the desire of most families to take more responsibility for the care of their own severely ill children and to have these children at home with the family, the growth of technologies allowing more miniaturization, and efforts at cost containment that encourage home care as a less expensive alternative to continuing in-hospital care. ${ }^{7}$

Technological advances, especially in genetics, are changing the preventive issues related to chronic health conditions. ${ }^{80}$ Two main genetic interventions exist: the ability to predict before conception the risk of conceiving a fetus with a given genetic disorder and the identification of an affected fetus early in pregnancy. Most recent advances in genetic technologies provide increasingly sensitive ways of defining the specific genetic defect, allowing earlier and much more exact determination of risk or disease. In addition, the detection of a fetal anomaly may now lead to termination of pregnancy or to other options, including a change in the timing or in the mode of delivery, or in prenatal treatment. Prenatal treatments include intrauterine surgery, ${ }^{81,82}$ transfusions, ${ }^{83}$ and delivery of medications to increase fetal survival rates and enhance peri- and postnatal development. Detection of a fetal anomaly may also allow the parents to be better prepared to deal with the special medical and other needs of an afflicted infant after birth.

Other recently developed technologies improve the lives of these children after they are born. There have been dramatic improvements in surgical techniques for the management of congenital heart disease, greatly improved medications for the treatment of leukemia and other childhood cancers, and therapeutic advances in the management of children with cystic fibrosis to lengthen their life spans. Children who are dependent on ventilators or who receive long-term intravenous feedings at home are examples of beneficiaries of other technological advances. Office of Technology Assessment estimates (figure 5) are that 20,000 to 30,000 U.S. children may require home care with significant technology dependence. ${ }^{84}$ Recent research suggests that the cost of home care can be exceptionally high, for some children well over $\$ 100,000$ per year. However, such costs are still lower than those typically associated with hospital care. Although some of these cost differences reflect true savings, many primarily reflect cost shifting from hospitals or insurers to parents. ${ }^{7}$

Children who survive with long-term chronic illness face risks of secondary disability, as well as higher risks of mental health problems and educational dysfunction. ${ }^{85,86}$ Multiple studies document that compared with apparently healthy children, children with long-term illnesses carry about twice the risk of having significant behavioral or psychiatric problems ${ }^{74,87}$ Most studies find that, with the exception of conditions that affect the central nervous system, all chronic illnesses whether severe or not seem to produce approximately the same increase in this risk. Children with chronic central nervous system conditions appear to have up to five times the risk of having significant behavioral or psychiatric problems as children without apparent illness. ${ }^{88}$

Chronic illness also significantly affects a child's ability to participate in regular education activities. ${ }^{89}$ Many developmental disabilities create the need for special education services that take into account the effect of the developmental problem on the child's ability to learn. Most chronic illnesses, however, create no direct impact on the child's ability to learn, although excessive fatigue and the effects of medi-

\section{Figure 5. Child Dependent on Technology, Population Estimates}

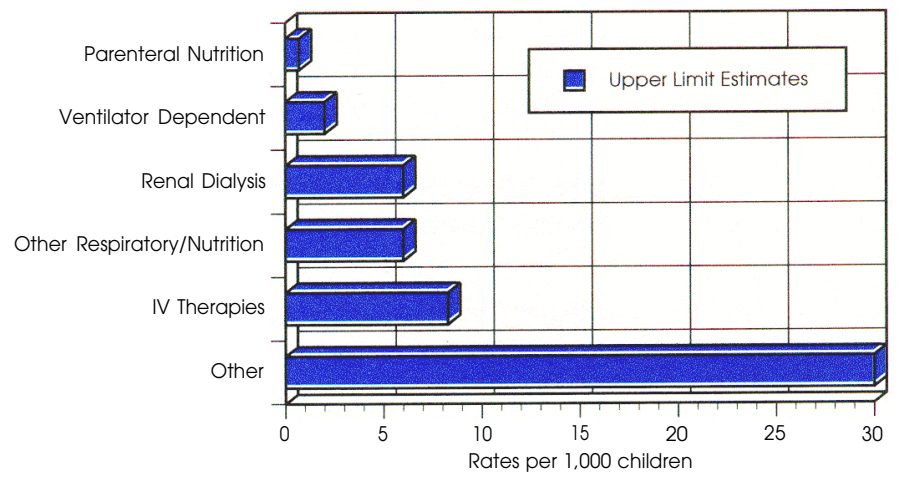

*Includes children assisted with devices such as urinary catheters or colostomy bags.

Source: Multiple data sources (mainly 1985-86). documented in U.S. Congress, Office of Technology Assessment, Technology-dependent Children: Hospital vs. Home Care. Washington DC: U.S. Government Printing Office(OTA-TM-H-38), May 1987. 
cation may affect the child's cognitive abilities. ${ }^{90}$ More commonly, the child faces frequent absences because of medical or surgical care or because of exacerbations of conditions such as asthma or arthritis. Many years ago, when the issue for these children was planning for premature death, schooling was considered relatively unimportant; today, with most children surviving to adulthood, there is a great need to improve educational opportunities and to diminish the effects of illness or its treatment on the child's participation in school. $^{91}$

Federal and state Title V Maternal and Child Health programs for children with special health care needs typically provide services for lowerincome children with chronic illness, though services vary greatly from state to state.

Most children with chronic illness have some public or private insurance for usual medical, surgical, and hospital care, but they often lack coverage for needed comprehensive and long-term care services. A recent Supreme Court ruling has led to expanded childhood eligibility for Supplemental Security Income and its associated Medicaid coverage, and poor children with disability may now find access to public insurance easier. ${ }^{92}$ Even for the large number of children insured through traditional employer-based family health insurance programs, many needed services have been unavailable or are not covered. Preexisting conditions clauses in insurance contracts may exclude chronic conditions, and specialized long-term care may not be included in the benefit package. (See the article by Sheils and Wolfe in this journal issue.)

Federal and state Title V Maternal and Child Health programs for children with special health care needs typically provide services for lower-income children with chronic illness, though services vary greatly from state to state. ${ }^{93}$ Some programs support hospitalization for children without other insurance, others fund specialized clinics for specific conditions, and others apply resources to coordination of services or to regionalized programs of care involving several medical and nonmedical disciplines. (See the article by Hill in this journal issue.)
Chronically ill children and their families need attention from a wide variety of health and related providers. They need specialized medical and surgical services, high-quality general health services (which they may lack more than do ablebodied children), specialized nursing services, social services, preventive mental health services, and specialized educational planning. Further, many need certain specific therapies, such as nutrition, respiratory therapy, and occupational and physical therapy. Given the variety of services many of these families use, they would probably find that care-coordination services, although often unavailable, would be very beneficial.

Optimal care for these children and their families would provide most services in or near their home communities while less frequently required specialized and technically advanced care of the child's medical problems could be provided through centralized specialty medical centers. ${ }^{73,94}$

Regionalized service networks may be necessary to forge the links between, community-based services and centralized specialty services which are necessary to improve the delivery of comprehensive care to children with chronic illnesses. Traditional health insurance programs which pay primarily for medical care services may not pay for the other services that families with chronically ill children need. Already financially strapped families may have to pay for these services out-of-pocket or do without them. In addition, traditional health insurance plans may not support the organization and maintenance of regional multidisciplinary programs. The development and maintenance of these programs may require significant expenditures and responsibility from other, usually public health, sources. In some states, the Title $\mathrm{V}$ programs have taken primary responsibility for developing and implementing a multidisciplinary approach to health care. ${ }^{95}$

\section{Conclusions and Recommendations}

The evidence suggests that neither the traditional personal health service delivery system nor the public health system alone can effectively provide all the health services children need. Collaboration between public health and personal health service providers is essential to assure adequate 
immunizations, prevent childhood injuries, ensure adolescents access to responsive preventive care, and provide a full range of specialty and comprehensive services to children with chronic illnesses and their families.

Most other industrialized countries employ a community-based system available to all residents regardless of income to link their personal health services and public health systems. The structures of such programs vary widely, from health visitors in Great Britain ${ }^{96}$ to community health centers in Norway ${ }^{97}$ to well-child conferences in France. ${ }^{98}$ Nevertheless, all of these countries provide a mechanism to address issues such as assuring and monitoring immunization levels, providing community education about injury prevention or aspects of adolescent sexuality, and helping to identify children with special health needs and to coordinate multidisciplinary care for them and their families. A similar system of community-based health care monitoring and coordination would greatly help the United States meet the health care needs of children.

Accordingly, we make the following five recommendations:

1. Develop community-based preventive care programs in all parts of the country. The forms and structures of preventive care programs may vary among communities, depending on resources and community needs, but all communities should have access to preventive services that screen and identify children and adolescents with health risks, help families gain access to needed health services, provide community health education, and assure high levels of illness prevention, especially through immunizations.

2. Extend current traditional primary care capabilities to provide satisfactory care for the health problems that children face, such as threats to development, chronic illness, and sexual and physical abuse. These changes will require improved professional school and in-service training for health providers and systems of reimbursement that assure equity between more procedurally oriented sickness care and the services needed to address new morbidity concerns.

3. Assure access to primary care services through such mechanisms as expansion of community health centers, both in number and in breadth of services. For many communities, especially those with large numbers of poor and disenfranchised households, multidisciplinary community health centers are the preferred mechanism for providing child and adolescent health services. Yet, many communities lack needed health centers. Furthermore, funding limitations in recent years have curtailed many multidisciplinary outreach programs and limited many programs to providing only office-based medical and nursing services. Community health centers need the resources to provide the range of services and outreach activities to meet community health needs effectively. Maternal and child health agencies need to assure that the systems of community health centers, county health departments, and private practitioners provide full coverage to all children and youth.

\section{Enhance public health activities. The} roles and responsibilities of public health agencies need clarification and support. At a minimum they should include identifying and monitoring child and adolescent health needs and services; setting and enforcing standards of care; implementing and maintaining systems of care, such as perinatal service programs and regional programs for children with special health care needs; developing community health education programs; preventing or eliminating environmental hazards such as lead; and providing certain direct services, such as immunization programs.

5. Expand specialized adolescent health programs. Although many adolescents receive adequate services through current community-based primary care programs, many others do not. Services should be developed in nontraditional settings for adolescents who lack services or for whom services are inappropriate for their needs. Programs should emphasize preventive care and provide comprehensive services rather than focus narrowly on issues such as sexuality or substance use. Two main efforts should be the expansion of schoolbased health programs and of programs in alternative settings where adolescents congregate. Although what works well for adolescents has not been clearly documented, it seems most important to provide multifaceted services in multiple, varied sites.

These five recommendations should be implemented through a coordinated program of care rather than through five (or more) competing systems of services. To achieve child and adolescent health goals, public health efforts must link with community-based preventive and primary care 
programs. The need is to link public and private systems of care to meet the health care needs of children and adolescents.
The authors acknowledge the helpful comments of Drs. Birt Harvey and Moses Grossman on an earlier version of this paper.

1. Harkey, J. Epidemiology of childhood chronic illness: An in-depth analysis. Unpublished staff paper. Vanderbilt Institute for Public Policy Studies, Nashville, TN, 1981.

2. Wegman, M.E. Annual summary of vital statistics, 1990. Pediatrics (1991) 88:1081-92.

3. Fingerhut, L., and Kleinman, J. Trends and current status in childhood mortality, U.S., 1900-1985. Vital and Health Statistics. Series 3, No. 26 (DHHS Publication No. 89-1410). Hyattsville, MD: National Center for Health Statistics, 1989.

4. Guyer, B., and Ellers, B. Childhood injuries in the U.S. American Journal of Diseases of Children (1990) 144:649-52.

5. National Center for Health Statistics. U.S. Department of Health and Human Services. National Hospital Discharge Survey: Annual Summary, 1990. Vital and health statistics. Series 13: Data from the National Health Survey No. 112, June 1992, p. 8. Hyattsville, MD: Centers for Disease Control, 1992.

6. Perrin, J.M., Valvona, J., and Sloan, F.A. Changing patterns of hospitalization for children requiring surgery. Pediatrics (1986) 77:587-92.

7. Perrin, J.M., Shayne, M.W., and Bloom, S.R. Home and community-based care for chronically ill children. New York: Oxford University Press. In press.

8. Maiman, L.A., Becker, M.H., and Kaltic, A.W. Correlates of mothers' use of medications for their children. Social Science and Medicine (1986) 22:41-51.

9. Ames, J.T., Hayden, G.F., Campbell, R.E., and Lohr, J.A. Parents' conception of their use of over-the-counter medications. Clinical Pediatrics. Philadelphia, PA: (1982) 21:298-301.

10. Guyer, B. Title V: An overview of its evolution and future role. In Children in a changing health care system: Assessments and proposals for reform. M. Schlesinger and L. Eisenberg, eds. Baltimore: Johns Hopkins University Press, 1990.

11. Klerman, L.V., Grazier, K.L., and Thomas, K.C. The role of the public sector in providing children's health care. In Children in a changing health care system: Assessments and proposals for reform. M. Schlesinger and L. Eisenberg, eds. Baltimore: Johns Hopkins University Press, 1990.

12. Clarke, A., and Walton, W.W. Effect of safety packaging on aspirin ingestion in children. Pediatrics (1979) 63:687-93.

13. McLaughlin, E., Clarke, N., and Stahl, K., et al. One pediatric burn unit's experience with sleepwear related injuries. Pediatrics (1977) 60:405-409.

14. Kahane, C.J. An evaluation of child passenger safety: The effectiveness and benefits of safety seats (summary). Washington, DC: National Highway Traffic Safety Administration (DOT HS 806-889), 1986.

15. Katcher, M.L. Scald burns from hot tap water. Journal of the American Medical Association (1981) 246:1219-22.

16. Gortmaker, S.L., and Sappenfield, W. Chronic childhood disorders: Prevalence and impact. Pediatric Clinics of North America (1984) 31:3-18.

17. Egbuonu, L., and Starfield, B. Child health and social status. Pediatrics (1982) 69:550-57.

18. Perrin, J.M., Homer, C.J., Berwick, D.M., et al. Variations in rates of hospitalization of children in three urban communities. New England Journal of Medicine (1989) 320:1183-87.

19. Haggerty, R.J., Roghmann, K.J., and Pless, I.B. Child health and the community. New York: Wiley, 1975.

20. Miller, C.A., Fine, A., and Adams-Taylor, S. Monitoring children's health: Key indicators. Washington, DC: American Public Health Association, 1989.

21. U.S. Department of Health and Human Services. Office of Human Development Services. Administration for Children, Youth, and Families. Children's Bureau National Center on Child Abuse and Neglect. Study Findings. Study of National Incidence and Prevalence of Child Abuse and Neglect: 1988.

22. American Academy of Pediatrics. New task force on coding of mental health disorders in children. American Academy of Pediatrics News, December 1991. 
23. Society for Behavioral Pediatrics. The breadth of developmental and behavioral services. Journal of Developmental Behavioral Pediatrics (1992) 13:7-10.

24. U.S. Congress, Office of Technology Assessment. Healthy children: Investing in the future. Washington, DC: U.S. Government Printing Office (OTA-H-345), February 1988.

25. American Academy of Pediatrics, Committee on Psychosocial Aspects of Child and Family Health, 1985-1988. Guidelines for health supervision II. Elk Grove Village, IL: American Academy of Pediatrics, 1988.

26. Casey, P., Sharp, M., and Loda, F. Child health supervision for children under 2 years of age: A review of its content and effectiveness. Journal of Pediatrics (1979) 95:1-9.

27. Yankauer, A. Child health supervision-Is it worth it? Pediatrics (1973) 52:272-77.

28. Reisinger, K.S., and Bires, J.A. Anticipatory guidance in pediatric practice. Pediatrics (1980) 66:889-1014.

29. American Academy of Pediatrics. Recommendations for preventive pediatric health care. American Academy of Pediatrics News, July 1991.

30. Foye, H., Chamberlin, R., and Charney, E. Content and emphasis of well-child visits. American Journal of Diseases of Children (1977) 131:794-97.

31. Korsch, B.M. Issues in evaluating child health supervision. Journal of Pediatrics (1986) 108:933-34.

32. Wagner, J., Herdman, R., and Alberts, D. Well-child care: How much is enough? Health Affairs (Fall 1989) 8,3:147-57.

33. Starfield, B. The effectiveness of medical care: Validating clinical wisdom. Baltimore: Johns Hopkins University Press, 1985.

34. Child health in 1990: The U.S. compared to Canada, England and Wales, France, The Netherlands, and Norway. Pediatrics (1990) 86: supplement.

35. National Association of County Health Officers. National profile of local health departments: An overview of the nation's public health system. Washington, DC: National Association of County Health Officers, 1990.

36. Lefkowitz, D., and Short, P. Medicaid eligibility and the use of preventive services by low income children. National Center for Health Services Research and Health Care Technology Assessment (1989). Cited by permission of author, November 21, 1991.

37. Adams, P.F., and Benson, V. Current estimates from the National Health Interview Survey, 1989. National Center for Health Statistics. Vital Health Statistics (1990) 10:176.

38. Homer, C.J., Perrin, J.M., Bloom, S.R., and Evans, A. Hospital use by children with chronic illness. Abstracts. Washington, DC: Ambulatory Pediatric Association (1989):28.

39. Orr, S., Charney, E., Straus, J., et al. Emergency room use by low income children with a regular source of health care. Medical Care (1991) 29:283-86.

40. National Commission Against Drunk Driving. Youth driving without impairment: A community challenge. Report on the youth impaired driving public hearings, December 1988. Washington, DC: National Highway Traffic Safety Administration.

41. Newacheck, P.W., and McManus, M.A. Health insurance status of adolescents in the U.S. Pediatrics (1989) 84:699-708.

42. American Medical Association Council of Scientific Affairs. Providing medical services through school-based health programs. Journal of the American Medical Association (1989) 261:1939-42.

43. Task Force on Pediatric Education. The future of pediatric education. Evanston, IL: Task Force on Pediatric Education, 1978.

44. U.S. Congress, Office of Technology Assessment. Adolescent health-volume 1: Summary and policy options. Washington, DC: U.S. Government Printing Office (OTA-H-468), April 1991.

45. U.S. Department of Health and Human Services. Office of the Inspector General. Runaway and homeless youth: National program inspection, Region X, October 1983.

46. National Network of Runaway and Youth Services. Runaway and homeless youth: To whom do they belong? Washington, DC: National Network of Runaway and Youth Services, 1991.

47. American Medical Association Council of Scientific Affairs. Health care needs of homeless and runaway youth. Journal of the American Medical Association (1989) 262:1358-61.

48. Williams, B.C., and Miller, C.A. Preventive health care for young children: Findings from a 10-country study and directions for U.S. policy. Arlington, VA: National Center for Clinical Infant Programs, 1991. 
49. Hinman, A.R. Immunization in the U.S. Pediatrics (1990) 86,6, supplement: 1064-66.

50. Centers for Disease Control. Tables from the U.S. Immunization Survey, 1985. Unpublished data. Atlanta, GA: Department of Health and Human Services, 1986.

51. Centers for Disease Control. Morbidity and Mortality Weekly Report (1991) 40:22.

52. Cutts, F.T., Orenstein, W.A., and Bernier, R.H. Causes of low preschool immunization coverage in the U.S. Atlanta, GA: Centers for Disease Control, 1990.

53. Dutton, D.B. Explaining the low use of health services by the poor: Cost, attitudes, or delivery systems. American Sociological Review (1978) 43:348-68.

54. Marks, J., Alpin, T., Irvin, J., et al. Risk factors associated with failure to receive vaccinations. Pediatrics (1979) 64:304-309.

55. National Vaccine Advisory Committee. The measles epidemic: The problems, barriers, and recommendations. Journal of the American Medical Association (1991) 266:1547-52.

56. Orenstein, W.A., and Atkinson, W. Overview and keynote address. Paper presented at Houston's Leadership Conference on Immunizations. Houston, TX, 1990.

57. Guyer, B., Barid, S.J., Hutcheson, R.H., et al. Failure to vaccinate children against measles during the second year of life. Public Health Reports (1976) 91:133-37.

58. McDaniel, D., Patton, E., and Mather, J. Immunization activities of private practice physicians: A record audit. Pediatrics (1975) 56:504.

59. Peckham, C., Bedford, H., Senturia, Y., et al. National immunization study: Factors influencing immunization uptake in childhood. London: Action Research for the Crippled Children, 1989.

60. Fingerhut, L.A. Personal communication with author, October 24, 1991.

61. Malek, M., Chang, B., Gallagher, S.S., and Guyer, B. The cost of medical care for injuries to children. Annals of Emergency Medicine (1991) 20:997-1005.

62. National Committee for Injury Prevention and Control. Injury prevention: Meeting the challenge. Published by Oxford University Press as a supplement to the American Journal of Preventive Medicine (1989) 5,3.

63. Fleming, G. Personal communication with author, 1992.

64. Thompson, R.S., Rivara, F.P., and Thompson, D.C. A case-control study of the effectiveness of bicycle safety helmets. New England Journal of Medicine (1989) 320:1361-67.

65. Wasserman, R., Wailer, J., Monty, M., et al. Bicyclists, helmets and head injuries: A riderbased study of helmet use and effectiveness. American Journal of Public Health (1988) 78:1220-21.

66. Weiss, B.D. Trends in bicycle helmet use by children: 1985 to 1990. Pediatrics (1992) 89:78-80.

67. Cushman, R., Down, J., MacMillan, N., et al. Helmet protection in the emergency room following a bicycle injury: A randomized trial. Pediatrics (1991) 88:43-47.

68. Cushman, R., James, W., and Waclawik, H. Physicians promoting bicycle helmets for children: A randomized trial. American Journal of Public Health (1991) 31:1044-46.

69. Runyan, C.W., and Runyan, D.K. How can physicians get kids to wear bicycle helmets? A prototypic challenge in injury prevention. American Journal of Public Health (1991) 81:972-73.

70. Gans, J., Blyth, D., Elster, A., et al. America's adolescents: How healthy are they? Chicago: American Medical Association, 1990.

71. Lear, J., Gleicher, H., Germaine, A., et al. Reorganizing health care for adolescents: The experience of school-based adolescent health care programs. Journal of Adolescent Health Care (1991) 12:450-58.

72. Williams, B.C., and Miller, C.A. Preventive health care for young children: Findings from a 10-country study and directions for U.S. policy. Arlington, VA: National Center for Clinical Infant Profile, 1991.

73. Hobbs, N., Perrin, J.M., and Ireys, H.T. Chronically ill children and their families. San Francisco: Jossey-Bass, 1985.

74. Cadman, D., Boyle, M., Szatmari, P., et al. Chronic illness, disability, and mental and social well-being. Pediatrics (1987) 79: 805-13.

75. Butler, J.A., Budetti, P., McManus, M.A., et al. Health care expenditures for children with chronic illnesses. In Issues in the care of children with chronic illnesses. N. Hobbs and J.M. Perrin, eds. San Francisco: Jossey-Bass, 1985. 
76. Heagerty, M.C. Pediatric acquired immunodeficiency syndrome, poverty, and national priorities. American Journal of Diseases of Children (1991) 145:527-28.

77. Chu, S.Y., Buehler, J.W., Oxtoby, M.J., et al. Impact of the human immunodeficiency virus epidemic on mortality in children, U.S. Pediatrics (1991) 87:806-810.

78. Van Dyke, R.B. Pediatric human immunodeficiency virus infection and the acquired immunodeficiency syndrome. American Journal of Diseases of Children (1991) 145:529-32.

79. Breslau, N., Salkever, D., and Staruch, K.S. Women's labor force activity and responsibility for disabled dependents. Journal of Health and Social Behavior (1982) 23:169-83.

80. Holtzman, N.A., and Richmond, J. Genetic strategies for preventing chronic illness. In Issues in the care of children with chronic illness: A sourcebook on problems, services, and policies. N. Hobbs and J.M. Perrin, eds. San Francisco: Jossey-Bass, 1985.

81. Harrison, M.R., Adzick, N.S., Longaker, M.T., et al. Successful repair in utero of a fetal diaphragmatic hernia after removal of herniated viscera from the left thorax. New England Journal of Medicine (May 31, 1990) 33,22:1582-84.

82. Harrison, M.R., Filly, R.A., Parer, J.R.T., et al. Management of the fetus with a urinary track malformation. Journal of the American Medical Association (1981) 246:636-39.

83. Berkowitz, R.L. Intrauterine transfusion, 1980: An update. Clinics in Perinatology (September 1980) 7,2:285-97.

84. U.S. Congress, Office of Technology Assessment. Technology-dependent children: Hospital vs. home care. Washington, DC: U.S. Government Printing Office (OTA-TM-H-38)) May 1987.

85. Newacheck, P.W. Adolescents with special health needs: Prevalence, severity, and access to health services. Pediatrics (1989) 84:872-81.

86. McManus, M.A., Newacheck, P.W., and Greaney, A.M. Young adults with special health care needs. Pediatrics (1990) 86:674-82.

87. Gortmaker, S.L., Walker, D.K., Weitzman, M., et al. Chronic conditions, socioeconomic risks, and behavioral problems in children and adolescents. Pediatrics (1990) 85:267-76.

88. Pless, I.B., and Roghmann, K.J. Chronic illness and its consequences: Observations based on three epidemiologic surveys. Journal of Pediatrics (1971) 79:351-59.

89. Walker, D.K., and Jacobs, F.H. Public school programs for chronically ill children. In Issues in the care of children with chronic illness. N. Hobbs and J.M. Perrin, eds. San Francisco: Jossey-Bass, 1985, pp. 615-55.

90. Weeks, K.H. Private health insurance and chronically ill children. Issues in the care of children with chronic illness. N. Hobbs and J.M. Perrin, eds. San Francisco: Jossey-Bass, 1985:880-911.

91. American Academy of Pediatrics, Committees on Children with Disabilities and School Health. Children with health impairments in schools. Pediatrics (1990) 86:636-38.

92. Perrin, J.M., and Stein, R.E.K. Reinterpreting disability: Changes in SSI for children. Pediatrics (1991) 88:1047-51.

93. Ireys, H.T., Hauck, R.J.P., and Perrin, J.M. Variability among state Crippled Children's Service programs: Pluralism thrives. American Journal of Public Health (1985) 75:375-81.

94. Stein, R.E.K., ed. Caring for children with chronic illness. New York: Springer Publishing Company, 1989.

95. Bilotti, G.E. The Illinois model: A statewide initiative. In Caring for children with chronic illness. R.E.K. Stein, ed. New York: Springer Publishing Company, 1989.

96. Goodwin, S. Preventive care for children: Immunization in England and Wales. Pediatrics (1990) 86:1056-60.

97. Lie, S.O. Children in the Norwegian health care system. Pediatrics (1990) 86:1048-52.

98. Manciaux, M., Jestin, C., Fritz, M., and Bertrand, D. Child health care policy and delivery in France. Pediatrics (1990) 86:1037-43. 